Notre Dame Law School

NDLScholarship

Natural Law Forum

$1-1-1962$

\title{
Who Can Determine What the Natural Law Is
}

George W. Constable

Follow this and additional works at: http://scholarship.law.nd.edu/nd_naturallaw_forum

Part of the Law Commons

\section{Recommended Citation}

Constable, George W., "Who Can Determine What the Natural Law Is" (1962). Natural Law Forum. Paper 72.

http://scholarship.law.nd.edu/nd_naturallaw_forum/72

This Article is brought to you for free and open access by NDLScholarship. It has been accepted for inclusion in Natural Law Forum by an authorized administrator of NDLScholarship. For more information, please contact lawdr@nd.edu. 
WHO CAN DETERMINE WHAT

THE NATURAL LAW IS?

George W. Constable

A CRITICal QUESTION - perhaps the critical question - which emerges from the contemporary debates about natural law is, Who can determine what the natural law is? Who are the ones to declare and interpret it for us? This question is perhaps most often heard from the skeptical practicing lawyer. But it arises also among the professional jurisprudents, as can be observed in the various expositions of natural law and the spirited attacks upon them. The focal point of controversy eventually (and often unconsciously) shifts, in the argument, from questions about the ends and usefulness of natural law, or about its content and applications, or whether it exists at all, to the underlying question, Who shall establish the correct version of it?

\section{The Prmacy of the Question}

A LOGIGAL REASON for the emergence of this one question as primary can be easily understood. Before one can appraise the end and usefulness of a law, one must understand what the law is; but before one can understand what it is, one must identify who the lawgiver is, that is to say, the source whence the binding law comes. But since it is claimed that the Creator and/or nature dictates the natural law and reveals $H$ is or its prescriptions only in and through the understanding of men, and since men's understandings are often in conflict and in many cases uncertain, the ultimate question becomes, Whose understanding can determine what laws God or nature has prescribed?

The practical working of this dialectic is best perceived through an examination of the reasons advanced for opposition to natural law thinking:

1) A common ground for opposition has been the fear that natural law will serve as a mere cloak for authoritarianism, whether fascist, ecclesiastical, or other. A system that purports to prescribe universal objective rules for human conduct originating in nature or nature's God and known through "reason" seems a ready instrument for the imposition of a regime of repression and intolerance by self-declared spokesmen for nature or God. It appears to be fundamentally antidemocratic. This thought is behind the criticism of Friedmann and Gerhart and many others. From such a criticism emerges the basic query, Who can claim the right to tell what natural law 
is? Tell us this, the critics say, for this will determine whether our fears will be quieted or justified.

2) A second criticism, arising from an opposite quarter, is that natural law is too democratic: it is used simply as a mantle to protect the will of the individual, especially in the matter of property rights. Natural law has, indeed, often been used as a cloak for the selfishness of landowners and capitalists, claiming vested and inalienable natural rights. This criticism raises the question of who can determine natural law in this form: Is not natural law for anyone simply what he wants it to be?

3) Both of these criticisms presuppose a third and underlying one. This criticism grows out of perception of the apparent subjectivity of natural law norms. Even supposing natural law is neither a device of authoritarians nor a mantle for individualists, still, a natural law which is apparently deduced from the thin air of metaphysics and theology can easily amount to no more than a rational articulation of unconscious personal inclinations having no relation to a universal or transcendental reality. It, therefore, serves to give a false certainty to the uncertain, thereby clouding vision and stifling progress. By making arbitrary opinion sacrosanct, it prevents legitimate inquiry, experiment, and reform. Here again, the primary query necessarily emerges under the form of the question, Is not natural law for any person simply what he thinks it is?

4) A fourth reason for opposition, closely akin to the third, is the alleged failure of natural law to provide any specific rules for application to concrete cases. It is alleged to be empty of meaningful content. "Do good and avoid evil." All the real questions are begged, for what is good and what is evil? The need of certainty and definiteness is clearly not met by a system that is vague and abstract on the one hand and variously interpreted and explained on the other. How can one know what the natural law is in a particular case? This is close to asking, Who can say, with finality, what it is in a given case?

5) A fifth reason for opposition - and this is the ultimate underlying philosophical reason - is the alleged failure of natural law theorists to explain how any natural "ought" can arise from any "is" in nature. Indeed, it would seem that Kelsen and other critics of natural law are right in attacking a natural law theory which purports to derive value from being and essence; that is, which claims that a man "ought" to act thus and so simply because it will perfect his essence or carry out certain tendencies of his nature. Natural law theory must not assume the very thing to be proved: the necessity of perfecting an essence, the obligation of carrying out some tendencies rather than others, or, for that matter, of carrying out any tendencies 
at all. Why must a man carry them out? Suppose he is ready to risk all the consequences: Why can he not defy his "natural" tendencies, or exalt one tendency at the expense of others? That a thing exists does not argue its right to continue to exist. Death is as much a part of nature as life. Nor does the fact that a thing normally occurs in one way argue that it must continue to occur in that way. Natural law theory, if it is to meet this criticism, must find a deeper basis for the "ought." Here again we are thrown back upon the primary question, What is the source of a binding "ought" and who can speak for it? The focus of this objection is directly on the alleged logical incomprehensibility of an identifiable source of a binding natural law.

This debate over the validity of the distinction between the law that is and the law that ought to be may be reducible to the jurisdictional question, Who can prescribe the ought? Any law is essentially an "ought," a directive of what ought to be. To distinguish between the legal is and the ought may be simply to make a distinction between the "ought" proposed by the State - through its courts, its legislature, or its executive, i.e., by the politically effective lawmaking authority - and the "ought" proposed by some other source, such as a moral or cultural authority or one's own conscience or ideals. It is fascinating to see how this underlying issue is obscured in the controversial writings. It seems much more realistic to state the issue in terms of choice among the lawmakers than in terms of "is" and "ought." After all, what we are debating is "whose 'ought' controls?" Obviously, someone's "ought" - i.e., someone's will - prevails in any case, for law is only directed toward human action where something is done or not done as a result of volition.

In any event, from whatever angle one attacks the natural law, the same underlying issue seems to come to the fore. But lest the problem appear peculiar to natural law theory, let it be noted at once that the same problem arises in all legal systems. It is crucial not only to natural law theories, but to the opposing schools of thought as well.

Ironically, the natural law critics of nonnatural law systems are moved by the same types of distrust that alarm opponents of natural law, that is, by a deep dissatisfaction with the potential authoritarianism, anarchy, arbitrariness and obscurity of theories not grounded in a transcendental purpose embodied in the structure of reality. It has been pointed out by critics of these theories that if one eliminates a transcendental purpose as the source of ethical value, one invites the very evils that one would be rid of. The door is opened to two competing doctrines: that each individual is his own lawgiver or that the most forceful person or group is the lawgiver. Thus the critic of natural law lays the rational foundation for either the chaos of in- 
dividualism or the dictatorship of a dominant group. Does not ethical relativism, in the end, mean that no purpose is binding upon a person except the purpose that is able to effect itself? It is no answer to say that people by and large are decent and that the dominant group will generally promote a beneficial system. One recalls that thousands of Nazis and Communists have legally justified their mass killings.

\section{Inadequate Dispositions of the Problem}

OUT OF THE DIALECTIC of mutual fears, the basic issue comes to be joined, pervading, indeed subsuming, all other issues. It would seem important to attack the question directly, and to do so as dispassionately and scientifically as possible. It will not suffice to continue to dodge the issue - each side pointing out the potential evil consequences of the other's position. This is to beg the question and leave unsolved the very problem upon which the validity of the mutual criticisms depends.

Nor will it help (except as between persons who already believe in natural law) to talk in terms of finding a common area of agreement - the "deontological" approach of d'Entrèves and others. Agreement about truth does not make truth or win over dissenters. It is not when we agree, that we are in greatest need of natural law, but precisely when we disagree, or when we do not know the answer to a problem of conduct. What law is to bind the dissenters (perhaps constituting a majority) who are committing a violation of the moral code of others while justifying themselves in so doing by their own code? How are we to condemn legalized tyrannies with any conviction or authority?

Some may attempt to dispose of the whole question as illegitimate. These say it is like asking, "Whose scientific truth is true?"; whereas scientific truth has an objective rational existence and structure, and is not to be determined on the basis of persons but of intrinsic accuracy. But such an objection is itself illegitimate and unrealistic. Each of us, as a living being, must act in one way or another; the choice depends on one's judgment of the relevant facts and values; judgments vary; therefore, there must be a decision whose judgment is to be followed. The problem simply cannot be banished. The navigator must decide whose charts are reliable when there are material differences. So every rational being must decide whose ways are good, whose rules are right, in the many cases where there is a great variety of opinion. The necessity of such a decision in no wise detracts from the objective structure of reality; in fact, the judgment selected may turn out to be entirely wrong, yet the selecting itself entirely proper and without culpability: Per- 
haps, the difficulty of solving the general problem influences the attempt to avoid it.

It may be suggested by some that the question is self-answering. Natural law, by definition, is precisely the law revealed by nature to man through the light of his own reason; and, therefore, it may be argued, there can be no substantial difference of opinion between reasonable men, or, if there are differences, then each man must follow only the light of his own reason. But this view seems inadequate. To say that there will be no substantial differences of opinion is to belie the innumerable instances of conflict even on such basic matters as the question whether there is any natural law knowable by reason. If we attempt to save the situation by adding the qualification that "reasonable men" will not differ, we have begged the whole question; for the very problem is to identify who are the reasonable men when there are differences of opinion.

Nor - granted the differences of opinion - is the problem solved by the notion that a man is bound only by his own lights, which is to say, his conscience. This overlooks the distinction between error itself and a culpable adherence to error. If there is any objective basis and structure to natural law, clearly every sincere opinion cannot be correct; and it will be necessary to make a choice. The opinion chosen may be objectively mistaken even if one follows one's lights, while the act of choice may be without blame in the eyes of God. Of course, if natural law has only a subjective basis, it is no longer natural law as always understood - that is to say, an objective norm of conduct binding all men at all times.

The undoubted truths of these several approaches to the basic problem, at least without further development, do not give the necessary philosophical underpinning to a fruitful employment of natural law jurisprudence for the needs of our era.

\section{The Beginning Point: The Kind of Knowledge Involved}

A PRRSON who undertakes to elucidate the problem risks being accused of secretly setting himself up as the determiner of natural law. This charge may be, and often is, just, but this is not necessarily so. One can tell others how to find a good mechanic to repair a car without one's self claiming to be a mechanic. One's ignorance is often the best guide. There is a valid distinction between determining the answer to a problem and determining the determiners of the answer. The latter does not necessarily indicate any improper self-exaltation. If it did, we would all be condemned in presuming to decide anything at all. 
Where shall we begin? If it is an inadequate answer to say that the natural law is determined by the "consensus" of mankind or by the "objective" structure of nature or by the "reasonable man" or by one's "conscience," how shall we determine it? It would seem appropriate to begin by inspecting what kind of knowledge is involved and then to proceed to ascertain the personal qualifications and conditions for attaining to this knowledge.

Here it appears that both the proponents and the opponents of the natural law tradition can agree in substance wherein it is that they disagree. While there are many ways of wording it, each with its own emphasis, there is basic agreement that what is being considered is the mind's supposed judgments of what conduct should be chosen or avoided as befitting or misfitting human nature necessarily and universally.

All understand that traditionally natural law, as the antithesis of ethical relativism, claims to lay down certain general rules of conduct that supposedly apply to all men, at all times, in all places.

Similarly, natural law, as a law, an "ought," purports to prescribe only what necessarily befits human nature. It is not an order of merely desirable actions, or of possible actions, or of customary actions.

Again, it is well understood that natural laws are directives addressed to movers who have the power, but not the right, to violate it. It is allegedly morally, not physically, binding. It presupposes free choice.

Also, it is understood that natural law purports to consist only in such directives of fitting conduct as may be discerned by the mind's eye - by human reason - unaided by extraneous authority. Natural law is claimed to extend to the area illuminated by the light of natural reason, no more, no less. A knowledge given by grace is not natural law knowledge. A knowledge, the authority for which is dependent upon scriptural revelation or tradition or upon a scholastic elite, is not natural law knowledge.

Universal, necessary, violable, discernible by natural reason - natural law knowledge purports to be all of these. But above all, natural law is understood to consist in the commands and prohibitions of those actions which befit or misfit human nature. Hence arises the term "natural law," i.e., the laws dictated by man's nature. This fitness is usually phrased in terms of goodness and similar terms, but the central concept remains, the suitability or fitness of human actions, or lack of it, to man's nature.

"Goodness" (used here in the sense of fitness), like health or beauty or truth, involves the perception of a relation. It involves both the thing which is adjudged good and a norm by which the observer measures it. It is the relation of conformity between a presupposed principle of order attributed to a thing as proper to it and the reality. By "principle of order" is meant 
that which gives entity to a diversity, making it a "thing"; it is the pattern, the form, the nature, of the thing; that which makes it what it is. In seeking the goodness of the thing, the fact sought is not whether, say, a table exists (its being); it is not even the fact of whether it is a table (its truth); it is whether it is a good or bad table - does it do what it is supposed to do? This type of relation, called a good or a value by an observer, involves (1) the attribution by the observer of a principle of order to the reality being judged, (2) the perception of the reality itself, and (3) the judgment whether the reality fulfills and perfects the presupposed principle of order. If it fulfills, it is called good; if it frustrates, it is called bad. So when we consider the goodness or badness of human conduct in general, there is a necessary reference to some principle of order supposedly attributable to man's activities, to a principle of immanent motion or inclination which gives order, oneness, individuality, to his activities - the controlling vital inclination. This operational principle is usually called the rational nature.

The attribution of the principle of order is, of course, the key to the matter. This is no particular problem with respect to human artifacts like a table, where the measuring principle for the goodness of the reality being judged is assigned by man. It is another matter with respect to things whose essence is not man-made. Thus, in the case of natural law, we are supposedly measuring human conduct not against a nature assigned by man, but against an inherent nature, an operating principle allegedly universally present in all men. Natural law undertakes to measure conduct by a principle identified with man's nature itself. Does man have such a universal operational principle? Is there such a thing as human nature? Or is man simply what he makes himself or what events make him? This is a question of fact - bio logical, psychological, perhaps even metaphysical fact.

There is a further possible pinpointing of the kind of principle of order involved in adjudging the goodness or badness of human conduct. Natural law, by definition, addresses its precepts not to the activities of a sleeping person or an animal but to the conduct of a deliberate mover, a conscious mind which can direct itself according to the ideas of things. As a supposed evaluation of rational conduct, natural law necessarily concerns itself with the movements of a rational mover. Therefore, the operating principle for which we must look in human nature as a basis of natural law must be a universally fixed principle by which a rational mover gives unity to his activities. Whether there is such a principle is, of course, another matter, but here again it is a question of fact.

It is immaterial to a determination of human nature whether men usually, or familiarly, or habitually incline to certain things; and it begs the question 
to say that man "should" naturally (i.e., by nature) incline to certain things. "Nature" is a description of the actual operative principle; it is not to be delimited to an ideal or customary or habitual operative principle. What we are looking for is precisely what, if anything, a rational mover does universally incline towards by virtue of his own interior disposition.

Natural law defined as the mind's perceptions of what is necessary and universally befitting the perceiver's nature - what is good or bad for him - is therefore based on the perception of the relation of man's actions to his controlling rational principle of movement. This is the principle of movement usually called volition, will, or rational appetite.

Furthermore, since all agree that man's rational movements - his acts of volition - are many, diverse, changing and often in conflict, not only as between individuals but also within each individual, it follows that if natural law is to have any specific and fixed content at all, it is necessary to find within volition itself some fixed direction, some unchanging principle of operation, by which to measure goodness. In other words, since the range of man's particular inclinations is "as large as the charter of the wind" - since he wants what he wants when he wants it - the only disciplining and ordering of all his inclinations that can be specified by a "natural law" will be that which will promote the accomplishment of a controlling inclination in deliberate human choice, if any.

There is no suggestion, in the concept of natural law, of "maximizing the satisfaction of human wants" or "seeking the greatest good of the greatest number"; no idea of the most efficient social engineering in the interest of the most pleasure and the least pain. The hierarchical principle of natural law is not some idea of numerical maximization of fulfillment of all inclinations but the idea of total fulfillment of a fixed inclination.

\section{The Obligatory Force of this Knowledge: The "Ought" of Natural Law}

SOME MAY OBJECT at this point: "You have performed a bootstrap operation: you have cheated in the argument by arbitrarily giving content to the natural law through fixing the definition thereof." But this objection cannot stand. All definitions purport to describe the content of the thing defined; and the proponents of natural law have a right to say, "This is what I meant by natural law when $I$ asked who can determine it."

Still, it may be urged: "This is too easy: you set the stage to answer the question of who can determine natural law by accepting as binding on all men the natural law as you define it. Granted your right to your own 
definition, the real problem is, What obligatory force does the natural law have as so defined? Why is anyone bound to the content which you give it?"

Translating this question into the terminology of our definition, this is to ask, Why must a person obey the general rules, if any, which are requisite for man's fulfillment of his prime inclination (in whatever it may prove to consist)? The answer is simple and is contained in the definition of natural law. Natural law is obligatory as the rational means whereby the rational mover carries forward the prime inclination operative in his volition. A rational creature is obliged to the extent and only to the extent that its commands and prohibitions are necessary to fulfill this prime inclination.

In what sense is a man free? The answer is, he is physically and psychologically free to the extent that he is free to act in any particular way; but he is not rationally free - that is, free from the compulsion of coherence since the means to carry out his intent are rationally compelling if he is to reach the end, and these natural law obligations are precisely, by definition, the means to this end. In other words, his obligation is moral and rational rather than physical or psychological. I am obligated to the means by the perception of its rational, logical necessity for the fulfillment of my basic inclination.

Thus, one does not have to act rationally, since obviously it is possible to ignore logic, to shut one's eyes to some of the consequences of choosing particular goods, to concentrate on intermediate ends at the expense of the ultimate one. A man is free to make his hell on earth. However, he cannot in reason complain about the consequences. He becomes irrational when he does so. He puts himself outside of natural law only by his self-blinding. He is therefore culpable in denying the obligation.

Furthermore, even when his ignorance is not willful, a rational creature will be bound by natural law (whatever its rules may be). He is bound in the sense that in violating it he makes the grievous mistake of inviting his own frustration; but he is not culpable. $\mathrm{He}$ is like the child who, through ignorance that the gun is loaded, shoots himself. The sanctions of natural law will differ for him, but not the prohibition itself against shooting people. For all his ignorance, the action is still foolish.

The criticism of natural law noted earlier, that there is no reason why a man is obligated to perfect his nature or essence if he is willing to risk the consequences, will lose its force if it be established that man does not really will the consequences but only deceives himself or is deceived as to his ultimate end.

In summary, the obligatory force - the "ought" - of natural law will bind through reason only, since it will arise out of the mind's perception of 
the necessary rational connection between the particular conduct and its necessary consequences of either fulfillment or frustration of man's fixed inner intendment.

\section{Personal Requisites for Determining Facts}

WE HAVE NOW A THEORY of the kind of knowledge that natural law purports to be and the implicit reason why such knowledge, if it exists, would be binding. The two chief questions to be answered, in determining natural law, are: (1) What, if anything, is the fixed inclination of the mind? and (2) What are the necessary forms of conduct to bring this inclination to success?

This brings us to our major inquiry - who can determine whether there is any such knowledge and its content if it exists? Reduced to this question, the problem does not seem insoluble, for this is a question of objective fact, not a purely subjective, relative value. It has a foundation in an is in contrast to an ought. It is the same kind of question that confronts us when we ask who can tell us what diet will make us healthy. The fact of a prime direction in human volition would, if true, constitute the fixed reference point for the perception of fitness; it would be the firm ground upon which to base the relational judgment of goodness.

The problems are indeed real and difficult, but are they not factual? Therefore, let us silence at its inception the mockery of the antiteleologicallyminded scientist. For the scientist has exactly the same problem: Who determines what scientific "truth" is true? History is replete with violent differences of opinion as to what the "fact" is, and with cases of "facts" that have become myths. To take certain examples at random: At various times almost every scientifically-minded person believed that the Ptolemaic scheme of astronomy was correct, that Newton's laws of gravity were completely accurate, that it was good to "bleed" people, that the earth was flat. These are now recognized as erroneous. Who determines this recognition of error? We do not observe that scientists are stultified by such a skeptical question, even though it is difficult to answer clearly.

The problem is like any other problem requiring the exercise of judgment as to facts. It presupposes two polar positions. First, it presupposes that there is a reality that transcends the determiner of it. Knowledge advances, becomes more refined, widens its perspective, corrects its conclusions, occasionally reverses itself; but the premise of this process is that there is an underlying fact independent of the fact-finders.

On the other hand, it presupposes that there is no knowledge of a fact 
without a knower. A fact, as receivable knowledge, must be formulated as truth in someone's mind. There must be a concept, a logos, a word, a law. The fact transcends the person who conceives it, but there still must be a conceiver, fallible though he may be. This will be more manifest in the case of facts which are invisible or which consist in relationships or processes or forces.

The problem is to establish the connection between these two terms the reality and the person's concept of it, the subject matter and that which someone predicates of it. This is not the place to set forth an epistemology. The problem is common to all fields of inquiry. For present purposes it suffices to note that, under almost any theory, not everyone nor anyone is at all times able to establish that the reality sought corresponds to his formulation of it as knowledge. Such a determination would seem to require such things as a clear understanding of the subject of inquiry, an opportunity to observe the evidence, the ability to perceive the steps of inductive or deductive reasoning that lead to the conclusion and back, the time and desire to concentrate on the proposition, independence from a motive that will distort or cloud one's judgment, the use of the appropriate method to arrive at the answer, inner coherence and pragmatic verification. The determination that a given formulation is a "fact" requires the determiner to be equipped and properly positioned in many different respects. This is to say that the factdeterminer must be qualified.

Few factual inquiries are so simple that every man is qualified for every aspect of the inquiry. Even the question "What time is it?" involves reliance upon countless other mental judgments in addition to one's own. One person may not have the mathematical capacity, another the detachment, another the opportunity or equipment to observe and/or calculate, and so forth. In most factual inquiries, a whole team of qualities will be necessary to meet the standards of qualification.

The central point is that the type of fact sought will establish how its determiners must be equipped, positioned, and operative. For present purposes, the personal qualifications may be conveniently classified in three basic categories: (1) the person must have mental capacity for dealing with the type of fact sought; (2) he must have motives not inconsistent with effective and honest inquiry; and (3) he must have a perception of the cogency of the formulation which he makes.

If we have met the first two qualifications we have not escaped from the personal factor involved in determining a fact and placed ourselves on the terra firma of purely objective reality. The third qualification, the per- 
ception of cogency, is an insight of the mind involving a grasp of the consistency of the factual conclusion with all of the evidence, that is to say, the logical coherence of the formulation of the fact. Although there are many techniques of demonstrating cogency - including the machinery of logic, mathematics, ordinary language, and scientific analysis - the perception does not exist apart from a perceiver. Since perceivers often disagree as to whether the cogency exists we still have the problem of identifying the mind that is master of the appropriate technique of demonstration. Here again the type of knowledge will provide the key to the type of demonstration required and point to the appropriate demonstrator. For example, the proposition that "it is raining" can be demonstrated by almost anyone, whereas it requires mathematical physicists to demonstrate the formulation " $E=M C^{2}$."

Who, then, shall determine whether a person is mentally qualified, properly motivated and perceptive of the cogency of a factual formulation? This pushes the question deeper but does not change the nature of the answer; for, after all, the qualifications of a person to determine a fact are themselves matters of fact which must be determined. Here, too, the determiner must be qualified. The question "Who is qualified to determine the truth?" we must answer in part by answering this question: "Who determines the qualifications and decides who meets these qualifications?" The same tests apply as in determining the original fact. This is something we see in operation every day. For example, we may have a sick child and we wish to know what is the correct medical cure. As laymen, we first judge that we are not qualified to prescribe the cure ourselves and, therefore, we seek a physician to do so. Not knowing who is a qualified physician, we consult various sources, such as friends, doctors, and nurses, to obtain the best opinion as to a qualified physician. The physician chosen may, in turn, advise selecting a specialist. In this way, there is a selection of the selectors of the qualified physician; and, if necessary, a selection of the selectors of the best physician; and so on.

The beginning of this process of selecting the truth-determiner necessarily lies in the judgment of the person who is seeking the particular truth. In the final analysis, each man is perforce his own judge of the truth in this: whether he determines a particular truth for himself or whether he selects another determiner of that particular truth (or partly both) or whether he selects the selectors, and so on, initially he must - because he cannot avoid it - determine for himself, at least implicitly, what are the criteria for qualified judges of the particular truth and whose efforts meet these criteria. He must establish his own idea of reasonable qualification and decide who offers it. This is an involved process in actual working. Nevertheless, the ultimate court of appeals is his own judgment of the fact of qualification to judge. 
At least in this initial act of establishing the criteria and facts of qualification, one necessarily identifies oneself as the judge.

Historically, the establishing of facts involves a complex combining, disassociating, and recombining of judgments in a vast and intricate selective process involving the threefold tests of capacity, motive, and cogency of demonstration. On the whole, there is a tendency for judgments to converge into schools of thought, lines of orthodoxy, and a consensus of the informed. In many areas there arises a consensus as to the broad substance of some matter, with variation as to details; or a consensus as to the relevant part of some matter and a difference as to the irrelevant part; or vice versa. On the other hand, there are many cases of the lone, but correct, genius and of the strongly persuasive minority view. In any event, as a subject is worked over through the centuries, there is a grouping and regrouping of judgments as the conclusions are tested, retested, refined and corrected. A "better view" tends to emerge.

This winnowing process does not assure, by any means, that one can identify with certainty the correct school of thought. On the contrary, the identification may be, and indeed often is, entirely wrong, as proven by subsequent discoveries. But it does simplify the process of discovering the truth in that it limits one's right to rely on one's own judgment and it narrows down the field of extraneous choice, because the principle of qualification is controlling - in the search for truth there is implied a duty to follow the judgment that seems to one at the time to represent the most qualified judgment. Ptolemy should be accepted until Copernicus persuades the learned world of astronomers to the contrary. Newton's theory of gravity should prevail until Einstein convinces the mathematical physicists of a better view.

\section{Personal Qualtfications: Mental Gapactty and Concern}

AlL of THIS applies to the determination of natural law. The definition of natural law established the basic qualifications by which to identify its determiners: (1) Since natural law is the mind's judgments of what conduct universally and necessarily conforms to a universally fixed principle of rational movements of a rational mover, obviously its determiners must have the intelligence to be able to perceive the prime inclination and what conduct conforms to it. It is not necessary that the same persons must determine both facts. (2) Obviously too, the determiners must be honestly looking for these particular facts. The mind's eye cannot see unless it looks. (3) Finally, the determiners must be persons who have a perception of the cogency of the formulations of the supposed factual answers. 
As to the first qualification we can immediately exclude the very young, the senile, the insane, and the moronic. We can also exclude those who are very sleepy, tired, or drugged, that is to say, those whose perceptive powers are dulled. In the case of the inquiry concerning a prime inclination, there obviously must be a certain analytical capacity. In the case of the search for the suitable conduct, there will be many situations requiring special talents, information, and experience. For example, one must exclude from the determination of whether a particular killing is evil or whether heavy drinking is bad, persons deprived of essential information concerning the aggressiveness or defensiveness of the killing, or concerning the consequences of heavy drinking. Each type of judgment will readily suggest the appropriate intellectual qualifications. The questions of who judges the facts of capacity and incapacity, and who judges the appropriate type of capacity, are, of course, themselves questions of fact requiring the threefold personal qualifications for their determination. Most of us are daily making many such practical judgments of mental capacity without feeling that our determination thereof is unwarranted.

As to the second qualification, the right motivation, we must exclude those who, though they may be capable of discerning the prime inclination or the goodness of conduct, as the case may be, do not, in fact, attempt to discern it. First of all are those who are simply inattentive to the particular matter, or who are diverted to other matters. Then there are those who do not believe that there is any rational nature and hence any necessary means of effectuation of its tendencies and who, therefore, do not seek the one or the other. There are also those whose will is influenced in such a way as to cloud their perception of good and evil. For example, there are persons whose judgment is warped by anger, lust, or envy; there are those who are under some duress and who fear to acknowledge the good even to themselves; and there are those who are gripped by some interior psychological prejudice, such as a cultural or family habit ingrained from early youth. Again the problem of who determines these facts of volitional disqualification is itself a question of fact calling for similar qualifications of its determiner.

Perhaps the most prevalent disqualification under this second category occurs with respect to those whose motive of inquiry is something else than the discovery of goodness in conduct. There are many whose first interest is some particular good, such as life, pleasure, wealth, or power, including the power of particular persons, classes, or races. Inquiry may indeed show that goodness is reducible to certain particular goods, but this should come at the end, not the beginning, of reflection. Otherwise the inquirer will necessarily have a distorted judgment. It is all-important to aim towards the right 
final end if we are to discover the right means. As an arch example, the Communists generally are motivated by the desire to promote the material interests of the proletariat, and as a consequence every perception that conflicts with this objective is dogmatically brushed aside. Not to be passed over in this regard are those who start with an intense desire to protect their personal interests, their property or power, for example, and look for a rational nature and a natural law to supply a bulwark. A more difficult question of qualification concerns those who start with a revealed religious dogma and assume ex fide that natural law is a mere confirmation and supplement of their dogmatic views. Both groups may be right in their conclusions; but it is necessary to weigh whether they operate from a motive that would tend artificially to force natural reason into preconceived molds.

All of these disqualifications operate because of some defect in the intellectual capacity, or in the will, or in both. The tests, of course, do not wholly exclude certain individuals. They only exclude individuals at those times and places in their lives where the tests operate. A person may easily perceive right and wrong on one occasion, and on another be totally unable to do so. In other words, the tests go to the situation of the person at the time, not to the person as such.

There are also those who are mentally capable of discerning the good, but who deceive themselves in order to justify choice of a good which involves an evil. For example, a greedy man, in seeking the good of wealth, blots out the evil of the fraud that he commits in order to get it. In a divorce, a person who loves another often blots out the injury to the innocent spouse. An ambitious man in his climb to power hides from himself his injuries to the people upon whom he has stepped. The culpability of this type of person rests upon the voluntary self-blinding that is involved. Hence, ironically, they are bound by the very natural law which they have disqualified themselves from determining. The paradox is explained by the psychology of the self-inducement of the darkness. ${ }^{1}$ In short, the moral judgment of an evildoer as to what natural law is should not be trusted. This is not to beg the question, provided that the content of natural law has a factual anchorage in the nature of the rational appetite.

1. The psychology of this in relation to God has been expressed thus: "for everyone that does evil, hates the light and does not come to the light that his deeds may not be exposed. But he who does the truth, comes to the light that his deeds may be manifest for they have been performed in God." John 3:20-21 There is an interesting question whether this self-induced disqualification to determine sin applies only to the particular sin or to others; and if the latter, then to what extent. This does not, of course, mean that it is not entirely possible to do evil and know and admit that it is evil. In other words, people are not compelled to close their minds but can determine the natural law for themselves even though they violate it and are subject to its penalties. 


\section{Personal Qualifications: Perception of Cogency}

After ALL of these exclusions, who is left to determine the two essential facts? There would appear to be left all of those whose minds are working coherently, with adequate skills and information, and who direct honest attention towards the discovery of the norm for goodness or the goodness itself, as the inquiry may be.

This leaves, one might suppose, quite a few hundreds of millions of the earth's billions. Presumably, it leaves "us." Though we have made some progress, our basic problem is therefore hardly solved, because "we" may disagree. On the other hand, to the extent of agreement among the qualified, the problem is in fact solved. Therefore, agreement itself among the clearly qualified is a kind of positive method of identification.

Unfortunately, while there is indeed a wide consensus, it cannot be said that all qualified persons agree either as to the prime inclination of men or as to the natural laws which will perfect that inclination. It becomes necessary, therefore, to consider not only the personal mental capacities and motivations of the determiners of the rational nature and of the natural law, but also the third qualification, the possession of a perception of the cogency of the findings. A valid determiner is to be identified through the quality of his formulation of the two key facts: the existence of a prime inclination and the means of carrying it out.

Determination of the universally fixed inclination.-Whose formulations, then, concerning a controlling direction in human volition are cogent? Perhaps the skepticism about natural law is largely based on the failure to see a convincing exposition of a prime intendment in volition.

A study of human motivation cuts across many disciplines - those of the biologists, the psychologists, the psychiatrists, the social scientists, the logicians, the moral philosophers, the metaphysicians, and the theologians. The historians and anthropologists also may have a claim on our respectful attention. And, of course, each person may often be the best qualified to know about his personal motivation by virtue of his intimacy with his own choices.

For convenience in examining what such qualified persons have to say that bears on the existence and nature of a fixed directional principle in the rational mover, the possibilities may be divided into two, and each of these again into two: (1) The volition (in the sense of the operative principle of rational movement) has no fixed direction either (a) because it is completely self-directing and autonomous or (b) because its direction varies according to the influence of the ever-varying finite causes operating upon it. 
(2) The volition has a fixed direction either (a) because there is a prime fixed finite cause determining it to some particular form of being or (b) because there is an infinite cause determining it which either (i) allows no freedom as to particulars or (ii) allows freedom as to particulars.

1(a) may be described as the god theory of volition or absolute autonomy; 1 (b) and 2(a) as the animal theories or material determinism; and 2(b) as the agent of God theory (filiation of a general creative motion). If 1 (a), $1(b)$, or 2(a) is true, there can be no basis for natural law: under 1(a) or (b) there will be no fixed operation principle against which to measure the goodness of human conduct; under $2(a)$ and $2(b)$ (i) there will be no freedom of the rational mover to choose the good. Only 2(b) (ii) will support a natural law in the sense described in this article.

As to the god theory of volition - 1(a) - there would seem to have been offered no cogent demonstration by the biologists, psychologists, metaphysicians, theologians or philosophers in general, that the will is completely autonomous; nor does personal introspection yield such a demonstration. This theory is tantamount to claiming that the rational mover gives himself his own power of motion; whereas every particular act we know of seems to require a prior act except in the one theoretical case of a self-subsisting act; and acts of will are clearly not self-subsisting. Something that itself comes into existence cannot be explained by a prior nothingness.

As to the animal theories of volition $-1(b)$ and $2(a)-$ it would seem appropriate first of all to consult those who seek to analyze scientifically the causes of human action. To begin with, the biologists and psychologists appear to make no claim that there is any single underlying, ever-present motivation in man. Certainly, they have established no such drive. The so-called organic or biological drives, such as the drives for air, water, food, correct temperature, muscular exercise, rest, sleep, sexual satisfaction, and life itself, are not irresistible motivations, as anyone may, and many do, turn aside and cut off any one of them by suicide or less drastic measures. The same ability to cut off and turn away holds for such drives as the pleasure-seeking, pain-avoiding drives; the drives to explore, to manipulate, and to master; and the drive for social approval.

The psychiatrists are perhaps more deeply involved in motivational theory, particularly as discovered in the subconscious. However, their findings hardly establish a fixed, universally present basic drive in deliberate actions. Perhaps the nearest suggestion of one is the Eros-drive singled out by Freud in supposed opposition to a death-wish. A case might be made out for a basic drive towards love itself, acting in a dual aspect of the desire to-be-loved and the desire to-love; but nothing definite seems to have been scientifically estab- 
lished here. Again, there is much attention given to the drive to communicate and to the whole idea of the necessity of proper interpersonal relations. Also, there is a recognition of the important role played by the so-called pleasureprinciple, and the general drive toward a release of tensions. However, the significance of these various drives to our inquiry is negative. It is doubtful whether any recognized psychiatrist would attempt to name a basic, irresistible, universal rational drive. In general, the approach of psychiatry has been pragmatic and therapeutical, dealing with aberrations and abnormalities. Its typical solutions arise in connection with various forms of tension, such as power versus community; individual versus security; ego versus superego; inferiority versus superiority; and Oedipus complex tensions. Theory seems to have eschewed such possibilities as free will and a purely spiritual drive.

The social sciences - politics, economics, sociology - appear to add little to our inquiry. The theories and findings in those fields assume, rather than prove, fixed ends of human nature, such as desires for freedom, power, wealth, peace, and cooperative living. There is no attempt to prove a dominant, irresistible, ever-present motive. Perhaps, the chief contribution that these disciplines can make is in developing the methods of obtaining the ends assumed to be correct. Also, they may supply conclusive historical evidence tending to verify or disprove theories of motivation advanced from other fields.

The logician working alone, and the historian and anthropologist working alone, have not solved and cannot solve our problem. The use of these disciplines in our inquiry would presuppose motivational data upon which to work.

Many philosophers and theologians have concluded that the one universal drive of human nature is towards happiness. Insofar as they mean nothing more than that the will tends towards the satisfying of all desires, that is, it seeks its own repose, this leaves our question up in the air since the content of happiness will be as variable as the desires. Insofar as they have attempted to assign universally fixed materially grounded desires, they have failed as much as the scientists to establish such universally fixed drives, and hence have begged the whole problem of determining universal prescriptions of good conduct.

It does not follow from the failure to demonstrate a scientifically measurable prime drive in motivation that the rational mover is free. It may still be true that the volition is a mere passive instrument of ever-varying material causes. In other words, the will may be determined, but not in a fixed direction; it may be indeterminate in itself, it may be extraneously but variably determined. However, while many persons may believe that a material cause 
is behind every deliberate choice, there would appear to be lacking at this point any cogent proof. Our consciousness of a power to will something to be for no other reason than we will it to be - our sense of a certain area of arbitrary personal power - hardly fits with such a theory. Furthermore, there is every evidence that man moves or is capable of moving according to abstract ideas like justice or love; and little proof that these ideas are caused by chemical, electronic, or other material causes. It strains credulity to assert that the volitional activity involved in the creation of Hamlet or in the formulation of the theory of relativity or in the life of a man like Gandhi is traceable entirely to some material cause.

Some philosophers, especially some metaphysicians and some theologians, who assign the drive towards happiness as the one universally fixed drive, do not attempt to reduce this drive to a material or even finitely based one. These thinkers have suggested that there is an infinite cause at work and that the universal direction is towards a happiness founded on vision or union with an infinite being. This brings us to the fourth theory, the agent of God theory, 2(b). It has been most fully and carefully worked out in scholastic philosophy. The will of a rational mover is viewed as necessarily and universally moving towards good apprehended as such, that is, the universal good. The will seeks goodness or universal being as the object of desire. The cause of this motion of the will is the Creator. Thus Aquinas in discussing "Whether the will is moved by God alone, as Exterior Principle" concludes as follows:

But the cause of the will can be none other than God. . . . First, because the will is a power of the rational soul, which is caused by God alone, by creation, as was stated in the First Part. . . . Secondly, it is evident from the fact that the will is ordained to the universal good. Therefore nothing else can be the cause of the will, except God Himself, Who is the universal good, while every other good is good by participation, and is some particular good; and a particular cause does not give a universal inclination. . . . God moves man's will, as the Universal Mover, to the universal object of the will, which is the good. And without this universal motion man cannot will anything. But man determines himself by his reason to will this or that, which is a true or apparent good.2

The will is said to be determined toward good in general but to be free with respect to particular goods, because it is grounded in a motion towards being as such. I believe that this theory is correct, but that the traditional proofs have been inadequate for our present needs and that the enormous

2. Aquinas, Summa Theologjae I-II, Q. 9, art. 6. See also Q. 10, art. 4; and Q. 8, art. 1 to the effect that "the will is of good only." 
significance of this conclusion is not sufficiently understood. I believe in particular that it is not fully grasped that this theory means precisely that there is a creative cause, Creator, directly involved in volition. My reasoning concerning the correctness of this theory is set forth in an extended footnote. ${ }^{3}$

3. It is suggested that the proof that our deliberate choices are powered by a creative motion lies in an analysis of what is required to explain both the restricting limits and the potential scope of free, deliberate choice.

Viewed from the outside, an analysis of human choices discloses a common restriction in man's selectivity that can have no other explanation. If a moving thing always moves towards an object, "X," among all the objects with which it is confronted, from no external or internal physical compulsion, then the moving thing must have within it (a) a means of perceiving " $X$ " and distinguishing it from "non- $X$ "; and (b) a power, "Y," moving the living thing toward "X." Now, the deliberate choices of man are so extremely variable and diverse that one may question whether there is a constant " $X$." The answer is in the affirmative; for while man chooses - without predictability - this thing or that, including nonactions, relations and negations, yet he always chooses a "thing," that of which being can be predicated by his mind, intellectual entity. Every object chosen is chosen as a thing, a unit, even "nothing." (See Summa I-II, q. 8, third objection and reply, dealing with nonbeings, privations and negations as "beings of reason" and hence goods which are objects of the will.) Therefore " $X$," in the case of man, is intellectual entity, "being" or unity as such.

As to the means of perceiving " $\mathrm{X}$ ": It seems tolerably clear that the perception of any unity in a diversity requires an encompassing medium of extension wherein the separate items may be seen, at once, both as separate and as related together. For example, the perception of the unity of a geometric figure requires immersion of the eye of the perceiver in an encompassing sense of spatial extension. In the case of intellectual unity, the encompassing medium can be none other than a sense of being, a pure existential light. And such a light must proceed from a cause equal to being.

As to the power, "Y," by which the mind moves directly toward being or "thingness": A power which moves directly toward being as such, is necessarily a cause of being, i.e., a creative power.

It would thus appear that, working back to the power implied in the common element present in the diversity of choices observable in human conduct, in choosing a course of action man chooses by virtue of being infixed, or seated as it were, in an interior act or motion which is immaterial, being-directed, creative.

If, on the other hand, we view human choice from within, subjectively, an analysis of the potential range of choice discloses the necessity of the same creative power to explain it. All deliberate choice presupposes that the chooser has within him a synoptic vision of the alternatives and a power to move in the direction of any of them. Now the alternatives before each one of us as a conscious, free, self-directing person are very wide indeed. They include, as noted above, not only concrete actions and objects of all types but negations and nonactions. The range is, in short, all intellectually conceivable things, or what has been called beings of reason.

The basis for a synoptic vision of all conceivable beings must necessarily be the light of being itself. This is because the basis for a synoptic vision of any given alternatives must be a reality which contains or encompasses the alternatives, so that the alternatives are simultaneously presented to the mind as possibilities. Thus a whole integer presents simultaneously to the mind its possible fractions. A stretch of land presents possible locations and paths. A power to accelerate a car presents possible speeds. But the only reality which encompasses and contains synoptically all conceivable beings must be the reality of being itself. Being is the whole matrix which presents to the mind possible participations of being. It is the basis of comprehending possible things. Even though we do not see it, we see by it.

The basis for moving among these alternative beings must be a motion which, containing the whole, can be applied to produce a participation. If there is such a motion 
There are those theologians who maintain that our every act is divinely predestined; that man's freedom is illusory; that we are merely pottery in a Divine Potter's hands. There is this logic behind this theory - assuming the prior proof of the existence of a First Being: such a Being would be the omnipotent sustaining Cause of all things that exist, and nothing could exist or act except subordinately to this Cause. However, while the age-old attempt to reconcile divine omnipotence with human freedom has certainly never been fully successful - always ending in mystery - it does seem that the debate presupposes the psychological observation of an area of human freedom and responsibility in particular choices and that the problem has been not whether it exists but how logically to reconcile this felt and observed inner self-control of man with the omnipotence of a First Being. Hence the theory

within man upon which he depends for his power of choice, it is clearly not a particular, finite, measureable motion. It must be intangible, infinite, and identifiable with a Creative Cause. Being free of the compulsion of particular actions, while capable of those actions, human volition must be free by virtue of being carried on a generalized, unparticularized, existential motion. "A particular cause does not give a universal inclination." To say this is simply to say that the power by which we choose is unbounded or infinite; hence, while operative within man's volition, it transcends that volition. It is the power by which the volition is free to operate. It does not violate freedom of the will; it explains it.

A pragmatic verification of the foregoing conclusion is as follows: The character of a satisfaction gives some indication of the type of operative power (drive) at work. For example, the satisfaction which we identify as pleasantness would seem to arise out of a successful release or expression of certain organic drives. On the other hand, the note of pleasantness is quite distinct from the note of volitional satisfaction. This satisfaction of the drive toward a deliberate choice has, rather, as its characteristic note, the note or savor of rightness, of suitability, of good. Therefore, it would seem to arise out of success in having realized some inclination (since the suitable is that which fits some given inclination). Must it not, therefore, originate in an inclination toward realizing inclinations? But such an inclination, reduced to its essence, is an inclination "to-make-to-be," since it is directed toward realization, a making real. It must, therefore, constitute a creative drive.

The general conclusion: In our deliberate actions, we ride along on an ongoing wave of existential action (creative, being-directed power). We are like surfboard riders being driven forward on the crest of the roller. The power comes from the ongoing wave; but the surfboard rider can deflect within limits the course of his surfboard towards one side of the beach or the other, or even let the wave pass him by. Or, we are like sailors on boats carried along solely by the wind. We go before the wind or tack at an angle to it. We may even head into the wind and lose all steerage-way. Whereas the power is the wind, the course on which the wind drives the boat depends on how the resulting motion given to the boat is used to steer the boat.

Herein lies the secret of the paradox that we find our freedom in submission to the Creator and our enslavement in our attempted independence.

In this age of the discovery of the powers of the atom and the relativity of clocks and yardsticks, it should cause no difficulty to suppose that in our conscious choices we are intellectually immersed in such a motion. It is not necessary that we see or picture it or even consciously feel it. We can see a thing by light without seeing the light. We can drive a car without seeing the motor. For all of its invisibility and elusiveness, we can detect the necessity of its presence and obtain the outlines of its general nature. No other explanation fits. The rational choosing activity of man must involve a superactive, all-inclusive motion. Perhaps the word "motion" is poor, because if a motion is all-inclusive, infinite, ubiquitous, and creative, it is so active as to be motionless. Unlike particularized motions, it is simultaneously everywhere, always, moving from all points to all points, like a pure existential presence. Indeed, perhaps it is best understood as a sort of pure presence in which all things stand in order to stand in the presence of each other. 
of complete divine determinism, 2(b) (i), for present purposes, seems to yield to 2(b) (ii), the theory of a divine determinism which somehow allows a certain amount of free choice.

Who is to decide which view is correct? Assuming personal mental capacity and honest intention, we can only weigh the cogency of the theories advanced by the various thinkers, just as in any other factual inquiry. Of the four possibilities, it seems to me that the case for complete autonomy and the case for some fixed finite drive have been insufficiently demonstrated. The case for finite but variable drives contradicts our sense of dignity, selfcontrol, personal responsibility, and capacity to move in accordance with abstract ideas. The case for a universal rational movement given directly by God is alone fully consonant with these realities. We must not be put off if the inquiry shows that volitional effects bear the marks of originating in a transcendent metaphysical cause, a creative cause. This conclusion may repel the scientist because it carries his inquiry beyond his tangible, measurable world of sensible reality; but his repugnance would not be very scientific.

The Determiners of the Content of Natural Law.-At long last we are in a position to answer the question, Who can determine what the natural law is? If there is demonstrated a complete indeterminancy of the will or a complete determinancy of the will whether by finite or infinite causes with no area of freedom, there can be no natural law; and no one can determine it. If, on the other hand, there be demonstrated a universally fixed general direction in the motions of the rational mover, with power in the mover to select particular directions, there is a basis of natural law.

There is no absolutely certain answer. In order to further the inquiry indeed, in order to decide when any conduct is right or wrong - it is necessary to commit oneself, at least implicitly, to some theory, and to proceed contingently based upon the decision. If the decision be in favor of the theory of a creative direction of volition with freedom as to particular applications (which I believe is the only possible basis of natural law), all those persons can determine natural law who, adopting creativity as the measuring norm of good or bad conduct, are qualified to perceive what befits this norm. It is not at all necessary that these persons prove to themselves that this must be the prime norm if in fact it is so - any more than a person must prove that a certain object is a table in order to adjudge it a good or bad table. The starting point can be assumed and adopted by the judge; it suffices that others have demonstrated it:

Goodness, then, we decide contingently, is to be found only in the conduct which befits a creative power. In other words, the natural law pattern which we are seeking is precisely that pattern of conduct of which the prin- 
ciple of order is the creative act. It is the order that will express aptly the motion toward being itself; the order that will image, not beings, but the Act of Being: God.

Our present inquiry is not to know the details of the order but rather to know who can discover these details. Of the three suggested lines of general competence - rational capacity, honest motive, and possession of a cogent demonstration - we have already discussed the application of the first two in general terms. However, now that a prime inclination is contingently assumed, some further significant conclusions can be reached.

As to rational capacity, including both reasoning power and necessary information, it will be seen that the intellectual equipment required will vary in accordance with the directness with which given types of conduct reflect the presupposed inclination. A creative motion is not visible or otherwise measurable even though it is the most real of things. It is an unbounded motion, an infinite motion, the simple act of making-to-be. Therefore, the visible, finite conduct that will befit and express this invisible, infinite motion will be in the nature of a shadowing forth, a making-present, an indirect representing. Some conduct will readily be seen to mirror the Creator; other forms of conduct will more obscurely mirror Him. Thus, almost everyone has the rational capacity to see that those acts which participate in growth, productivity, construction, expansion - in short, which express creativity will be called for by natural law; and, similarly, those things which stifle, restrict, suppress, or destroy will be prohibited by natural law. It does not take much mental capacity to see that murder as ordinarily defined is against natural law. However, since the world contains an immense diversity of inclinations and since production by one thing often involves harm to another, the problem of expressing creativity becomes exceedingly complex and requires the development of a hierarchy among beings based on a common subordination to the creative principle. The resolution of such conflicts as that caused by the need of repressing the aggressor or destroying the destroyer requires not only analytical capacity but a great deal of information as to the possible effect of given actions. In other words, the qualifications of a person to determine natural law will become more severe the more remote the relation of the act to the prime norm becomes.

As to the possession of an honest motive in determining natural law, it will be seen that according to the theory of volition adopted, there is built into the very nature of the functioning mind an honest motive, that is, the search for goodness. We incline, when we act deliberately (including making the act of inquiry), precisely toward universal good, or goodness, whether we realize it or not. Goodness is the object of the rational appetite. As such 
it derives its "taste" from the character of the operative principle of the deliberate act. Therefore, just as the note of satiety represents the sense of sufficiency of the food to the nutritional drive (hunger), or just as the note of pleasantness usually consists in the successful release or exercise of various organic drives, so our sense of goodness under this theory will consist in a kind of mental feeling for the aptness with which our actions articulate that which moves us to goodness. This feeling or taste draws the mind along and guides it as an artist is guided by a feeling for form.

These facts mean that it is entirely possible for a person to understand what the means to his end are without his knowing either the final end itself or the first beginning. In living things the end is simply the conformity of the means with the beginning - it is the aptness with which the means expresses the directing inclination. The aptness of the expression can be determined experimentally, by "savor." Therefore, to act in keeping with our character does not require foresight of our entire career or of our ultimate origin or destiny any more than to unfold a pattern by a step-by-step application of its motif requires a foreknowledge of either the designer or the whole ensuing design. If we have, in fact, a basic direction in the line of our life, we can project it fittingly inch by inch into the unknown, guided by the savor of its rightness. The idea of giving being, of doing good, is the basic direction with its special savor.

Thus, in the end the ability to know natural law, as it turns out, will depend in many cases neither upon our demonstration of our own natural operating principle, nor even upon the precision of our intellectual vision of this principle or its applications. The sense of good and evil will operate on our judgment quite independently of our clear understanding of the primacy of the inclination toward being, just as the sense of pleasure or pain over certain things will arise even though we may not be fully conscious of our inmost desire. The acts on the side of giving being will give a sense of right and approval, and those on the side of destruction will produce a sense of evil and guilt.

It may be thought that in saying that all men rationally will goodness we are implying that there is no room for any other motive in human action. This is not true. There are other motives than the rational appetite. Furthermore, the object of the rational appetite can be misconceived.

This may be explained as follows. The character of the power operative in deliberate action (volition) defines the order through which perfection will arise. If we look closely at the apparent freedom of man to choose anything that appears as a "being," we discover that the operative power must be a creative power, which is to say God. The power is God, but the form 
that the use of the power takes is given by man. Power is one thing; the virtue or defect in the resulting act is another. Good or evil, culpability or merit, can arise because the arrangement of the particulars in the pattern is not compulsory. We can refuse to image creative power, not because we do not want to image it, but because - wanting something lesser - we can close our eyes to the fact that our most free and deliberate self wants to image it, with the result that we use the very creative motion within us to emphasize particular objects at the expense of the overall object. The result is a distorted image, a deformity, a moral ugliness, a wrong. A noble power is turned to evil by its disproportionate use, just as the powers of growth can run wild in a body and cause deformity. In this way - by closing his eyes, by refusing to acknowledge his end - man can overlook the creative program and be chargeable with his failure. He has these two warnings which convict him: one, the voice of his sense of goodness which, like the aesthetic sense of a painter, serves as a monitor of the rectitude of his actions; the other, the intellect's reasonings of what will express the creative principle. Ignorance can be innocent; but when it refuses light, it can be guilty.

It will be noticed that being-minded ethics are those generally urged by the voice of conscience. This fact, in turn, tends to verify the finding of a creative bent in volition. For conscience is a certain connatural savoring of the rightness or wrongness of actions, and the almost automatic sense of rightness or wrongness that occurs when we consider life-giving or destructive conduct would indicate an innate drive toward being as such. This is not necessarily to identify conscience in all respects with the sense of goodness.

Now among those who have these two qualifications - who possess the intellectual equipment and who attend to the sense of goodness - there appears to be a fairly wide consensus of what conduct is universally good or evil. Nevertheless, this consensus is limited both as to the participants in the consensus and as to the type of conduct covered: Capable minds are often in conflict; and consciences too often do not agree, or are silent, or the scope of conscience is not understood. Thus natural law has been invoked on both sides of polygamy, birth control, euthanasia, slavery, racial segregation, the divine right of kings to rule, and the inalienability of various types of property rights. These differences and many others are not resolved by any appeal to a consensus based on rational capacity and good motive.

Therefore, to determine the natural law it will often be necessary to advert to the cogency of the derivation of the natural law from the application of the presupposed prime inclination. We can fix at least this one important condition by which to ideritify a cogent determiner: does the have a 
clear understanding of the prime norm? All tests of cogency must begin with this understanding.

What is it to act to express a creative motion? It is to communicate the principle of being, or at least to participate in some aspect of a process of communication of the principle of being; that is to say, it is a kind of evocation of a pure communication. But is this not, purely and simply, to do good for the sake of goodness, to love love? Therefore, in saying that the perfection of man is to participate in the expression of a creative act, we are saying that the perfection of man is precisely in the very act of loving. Here we find an abundance of support, not only from religious teachers and moral philosophers, but from sociologists, psychologists, and psychiatrists as well.

According to this theory, the peculiarity of the object of man's love lies in this, that the ultimate beloved is the Act of Love itself. The will inclines toward the act of communicating being and not toward any particular communication of being, except as a function of expressing the general inclination. This is the same as saying that the objective of the will is a Subsisting Goodness itself, as distinguished from any particular goods. Happiness therefore will not consist in life or any other particular goods, except to the extent, and only to the extent, that these particular goods contribute to a realization of goodness itself. Happiness will arise from the operation, the process of doing good, and not from special goods in themselves.

With this prime type of operation in mind, one is in a position to note the mistakes and confusions which have arisen in natural law theory because some particular good - like life - has been made more absolute than the process of doing good. Since exceptions can easily be found when such a particular good or any other particular good is not, in fact, primal, the whole hierarchical scheme is then thrown into disrepute. For example, if life is deemed the absolute, then natural law would prohibit any killing whatever, including voluntary self-sacrifice by soldiers. Common sense is forced to intervene and make exceptions which have no logical explanation.

But if creativity - love, goodness itself - is made prime, no exceptions are necessary and logic is preserved. Nor is this claim unrealistic. For reflection on one's practical experience will show that it has a wonderful power of explaining many apparent mysteries of conscience and of traditional natural law teaching. If the act of love be the true form of volitional perfection, then it becomes clear how happiness can be found in voluntary sacrifices and even in death for a constructive cause; how pain can be endured and pleasure shunned and happiness still obtained; why wealth and power in themselves are nothing; why true advantage to self can never be derived through injury to another; why suicide is not permissible; how the love that 
would justify mercy-killing is to be distinguished from the love founded in creativity; why freedom alone is insufficient for happiness; why communicating falsehood is inherently evil; why receiving what does not eventuate in giving is unsatisfying; why to suppress a natural religious faith in a Creator is a wicked thing.

Through all of these instances will be seen to run the explanatory common theme of outgoing love, of creativity. This, indeed, is, according to the pro posed solution, the only possible theme of natural law. Under the premise, all of the various drives operating in man should be allowed or denied strictly on the basis of their contribution to a creative pattern, for only thus will there arise the note of happiness and goodness. The desire for life, pleasure, power, friends, health, wealth, and every other particular thing should be subordinated to the operation of outgoing action. This should supply the basis of coordination among all the diverse ends clamoring for attention. In other words, conflicts among diverse claims should be settled by relating them to the creative scheme.

On an ultimate analysis, it would seem that a systematic development of a creative pattern - since many beings live and grow at the expense of others - will involve a hierarchical arrangement of creatures according to functional abilities, whereby the lower beings promote the well-being of the higher in an ascending scale, all leading toward a manifesting of the presence of the plenary Cause of being. In such a scheme, man will be a lord over lesser creatures and a servant under God. There is involved both an ennoblement and a liberation of man - an ennoblement with the duties of a high office in articulating the creative pattern, and a liberation with the rights and privileges pertaining to that high office.

The recognition of these three qualifications to determine natural law - rational capacity, good motive, and ability to develop demonstrations from a clearly understood prime norm - should narrow greatly the area of disagreement. Disagreements among the qualified will continue to exist, but they will be largely peripheral and should not obscure a great central area of agreement.

Such a natural law consensus is not and cannot be static. There has been and will be gradual refinement and correction. The dialectic of history exposes error, as does an individual's personal experience. Incorrect conclusions are reduced to absurdity, and impure motives that distort the judgment are purged. Applications vary as circumstances change. There is also a process of a more and more remote derivation of the less general from the more general. 


\section{Unresolved Contradictions Among the Qualified}

IF THE CONCLUSION of one qualified member of society is in conflict with the conclusion of another as to what the natural law is in any given case, then, $e x$ definitione, each is justified in following his own lights; even though the conclusion of one or both may eventually prove to be partially or totally in error. Men can, and quite properly do, contend for what appears rational to them. The logic of the idea of natural law is itself the justification: it makes each man's reason insofar as "reasonable" the ultimate judge of who the determiners of natural law are. To be sure, each is subject to the authority of the objective structure of the given fact as he sees it. To be sure, there can be error. Still, where there is a bona fide dispute, each has no alternative but to contend for his views. Events then must be the judge. If this produces war, the fault is with the cause of ignorance and not with men of honest minds.

The judgment of the truth of something presupposes good faith with respect to it. Every man is responsible for his own good faith. He is not free to invent a fact, nor is he at liberty to suppress a fact, nor again may he avert his eyes to create a willful ignorance. Again, he may not arbitrarily reject the views of those who by his own criteria are apparently qualified to speak. No man can be an authority for determining a fact unless he is honest with himself in his search.

It is in the foregoing sense that, classically, the natural law has been said to have its source in "reason" - not in the sense of the originator of the natural law (for that is the Author of nature), nor in the sense of the discoverer of it (for that is man), but in the sense of the criterion by which the discoverer identifies and measures the work of its Originator and its discoverer, i.e., its rationality.

\section{Conclusions}

WE COME BACK to our beginning. The skeptical question "Who can determine the natural law?" is grounded on reasonable fears and doubts. These include (1) the fears that natural law could constitute an instrument for a hateful authoritarianism, or a justification for unbridled individualism, or a sanctification of vested interests; (2) the apprehension that natural law is no more than a vague, arbitrary set of norms whose subjectivity only serves to stifle progress and obscure clear vision; and (3) the underlying doubt that any knowable determiner of natural law can be identified where there is a difference of opinion, since no "ought" can be seen to arise from an "is." 
The traditional reliance upon the concepts of reason, consensus, conscience, and the objective structure of nature as the basis for determining what the natural law is, has proved inadequate to remove these contemporary doubts.

The answer given in this paper - which gives due recognition to the importance of these concepts but finds a foundation in qualified factual analysis of human volition - should allay such fears and doubts. In the first place, a system of precepts for effectuating goodness in conduct, discovered by the intelligence, anchored in the objective fact of the free, creative bent of volition, is authoritarian only in an acceptable sense. It does not involve any human tyranny. It does not establish any political, social, racial, or clerical elite. It gives to all rational persons a franchise, and among these no one can claim superiority. All are subject to correction, whether priest, ${ }^{4}$ king, or democrat. In the end, it is intellectual cogency that constitutes the authority to which natural law calls us to bow - the cogency of the proposed law as the means to man's end as each sees this cogency in good faith. Natural law is precisely the disciplinary means to convert the world from a wilderness into a garden for the free play of the creative inclinations of man. A system that represses and frustrates the free creativity of men in the interest of a special economic class - Communism, for example - is therefore not a natural law system. On the other hand, a democracy which puts all the emphasis on freedom and little on man's duty to act constructively can err as much as Communism. While the system of natural law, aiming at volitional effectiveness as it does, guarantees human freedom, including property rights, it does not permit a selfish individualism, but calls for a constructive use of one's abilities and property. It requires that freedom must be exercised within the ambit of the duty to do good.

Thus understood, natural law, then, is not a system of vague subjective norms, since the norm, goodness, has an objective basis in that it represents the patterns of behavior which conform with a specified prime living inclination of the rational nature - the very act and process of doing good, of communicating being. Natural law as a system for bringing about such a conformity on a universal basis is therefore neither useless on the one hand, nor harmfully vague on the other. It promotes progress rather than stifles it. Natural law illuminates rather than obscures vision of what is good and evil.

4. Catholics believe that the Pope has an infallible power, under certain conditions, to determine matters of faith and morals (within the scope of the revelation given by scripture and tradition). This purports to include the natural law insofar as necessary to protect and support the truths of revelation. This claimed papal power does not derive from natural law and is not considered here in determining what are the natural qualifications of the determiners of natural law. In any case, by whomsoever the natural law is properly determinable, the Pope is himself subject to natural law. 
Finally, the origin of the natural law "ought" in the "is" of the mind's ever operative principle of rational choice - the motion toward good, being - is comprehensible, though intangible and immeasurable. Indeed, it is so intimate, immediate, and fundamental to our intellectual choices that we are often blind to its comprehensibility, just as, in looking at things, we rarely advert to the necessity of the fantastically active motion of the light by which we see them. 